\title{
The bioelements, the elementome, and the biogeochemical niche
}

\author{
Josep Peñuelas, ${ }^{1,2,8}$ Marcos Fernández-Martínez, ${ }^{2,3}$ Philippe Ciais, ${ }^{4}$ David Jou, ${ }^{5}$ Shilong Piao, ${ }^{6}$ \\ Michael Obersteiner, ${ }^{7}$ Sara Vicca, ${ }^{3}$ Ivan A. Janssens, ${ }^{3}$ and Jordi Sardans ${ }^{1,2}$ \\ ${ }^{1}$ CSIC, Global Ecology Unit CREAF-CSIC-UAB, Bellaterra 08193 Spain \\ ${ }^{2}$ CREAF, Cerdanyola del Valles 08193 Spain \\ ${ }^{3}$ Research Group Plants and Ecosystems (PLECO), Department of Biology, University of Antwerp, Wilrijk B-2610 Belgium \\ ${ }^{4}$ Laboratoire des Sciences du Climat et de l'Environnement, IPSL, Gif-sur-Yvette 91191 France \\ ${ }^{5}$ Department of Physics, Universitat Autònoma de Barcelona, Bellaterra 08193 Spain \\ ${ }^{6}$ Sino-French Institute for Earth System Science, College of Urban and Environmental Sciences, Peking University, Beijing 100871 \\ China \\ ${ }^{7}$ International Institute for Applied Systems Analysis (IIASA), Ecosystems Services and Management, Schlossplatz 1, Laxenburg \\ A-2361 Austria
}

Citation: Peñuelas, J., M. Fernández-Martínez, P. Ciais, D. Jou, S. Piao, M. Obersteiner, S. Vicca, I. A. Janssens, and J. Sardans. 2019. The bioelements, the elementome, and the biogeochemical niche. Ecology 100(5):e02652. 10.1002/ecy.2652

\begin{abstract}
Every living creature on Earth is made of atoms of the various bioelements that are harnessed in the construction of molecules, tissues, organisms, and communities, as we know them. Organisms need these bioelements in specific quantities and proportions to survive and grow. Distinct species have different functions and life strategies, and have therefore developed distinct structures and adopted a certain combination of metabolic and physiological processes. Each species is thus also expected to have different requirements for each bioelement. We therefore propose that a "biogeochemical niche" can be associated with the classical ecological niche of each species. We show from field data examples that a biogeochemical niche is characterized by a particular elementome defined as the content of all (or at least most) bioelements. The differences in elementome among species are a function of taxonomy and phylogenetic distance, sympatry (the bioelemental compositions should differ more among coexisting than among non-coexisting species to avoid competitive pressure), and homeostasis with a continuum between high homeostasis/low plasticity and low homeostasis/high plasticity. This proposed biogeochemical niche hypothesis has the advantage relative to other associated theoretical niche hypotheses that it can be easily characterized by actual quantification of a measurable trait: the elementome of a given organism or a community, being potentially applicable across taxa and habitats. The changes in bioelemental availability can determine genotypic selection and therefore have a feedback on ecosystem function and organization, and, at the end, become another driving factor of the evolution of life and the environment.
\end{abstract}

Key words: bioelements; biogeochemical niche; ecological niche; ecosystem function and organization; elementome; evolution; phylogenetic distance; plasticity; sympatry.

\section{The Elements of Life And the Construction of Molecules, Tissues, Organisms, And Communities}

All living beings are made of atoms of various bioelements (elements used by living organisms). The most common bioelements are hydrogen $(\mathrm{H}) 59 \%$, oxygen $(\mathrm{O})$ $24 \%$, carbon (C) $11 \%$, nitrogen $(\mathrm{N}) 4 \%$, phosphorus $(\mathrm{P})$

Manuscript received 10 October 2018; revised 26 December 2018; accepted 16 January 2019. Corresponding Editor: Diane S. Srivastava.

${ }^{8}$ E-mail: josep.penuelas@uab.cat
$1 \%$, and sulfur (S) $0.1-1 \%$ (percentages are of the total number of atoms in organisms; Slade 2006). C, H, and O are the basis of organismic structure, i.e., water and primary structural molecules, whereas $\mathrm{N}, \mathrm{P}$, and $\mathrm{S}$ enter in the various biomolecules allowing biochemical reactions. $\mathrm{C}, \mathrm{H}$, and $\mathrm{O}$ from $\mathrm{CO}_{2}$ and $\mathrm{H}_{2} \mathrm{O}$ are converted into the skeleton of all types of organic molecules by photo- and chemosynthesis. The molecular structures that control life processes (e.g., RUBISCO or chlorophyll), that carry information (e.g., DNA and RNA), and that control the storage and release of energy when and where necessary 
(e.g., ATP and NAD) all incorporate N, P, and, in lower amounts, $\mathrm{S}$.

These six bioelements, however, are not the only bioelements that have important roles in organisms (Slade 2006). Other bioelements, normally present in low concentrations such as potassium $(\mathrm{K})$, magnesium $(\mathrm{Mg})$, iron $(\mathrm{Fe})$, calcium $(\mathrm{Ca})$, molybdenum $(\mathrm{Mo})$, manganese $(\mathrm{Mn})$, and zinc $(\mathrm{Zn})$ have functions that are more specific. They are cofactors in catalytic reactions in several biochemical and physiological processes. For example, in plants, $\mathrm{K}, \mathrm{Mg}, \mathrm{Fe}, \mathrm{S}, \mathrm{Ca}$, and $\mathrm{Zn}$ are involved in photosynthesis, respiration, regulation of ion balance in chloroplasts and vacuoles, transport of sugar into the phloem, secondary metabolism, maintenance of internal cellular osmotic or $\mathrm{pH}$ equilibria and balances, and strategies for stomatal control and avoidance of water stress (Knight et al. 1991, Bourgis et al. 1999, Shaul 2002, Tripler et al. 2006, Peñuelas and Sardans 2009, Naples and Fisk 2010, Baribault et al. 2012, RivasUbach et al. 2012, Peñuelas et al. 2013, Sardans and
Peñuelas 2015). All these bioelements thus contribute essentially to organismic functions, albeit to different degrees (Fig. 1).

The concentrations and ratios of $\mathrm{C}, \mathrm{N}$ and $\mathrm{P}$ have been the basis of ecological stoichiometry (Elser et al. 2000a,b, 2001, Sardans et al. 2015, 2016a,b). However, to link bioelemental composition and stoichiometry with ecological traits in all types of organisms and communities will thus require information about bioelemental composition beyond the C:N:P concentrations and ratios (Peñuelas and Sardans 2009). The other bioelements such as $\mathrm{S}, \mathrm{K}, \mathrm{Ca}$, or $\mathrm{Mg}$ are also crucial and can be limiting in some ecosystems (Naples and Fisk 2010, Baribault et al. 2012, Lapenis et al. 2013). These other bioelements have been introduced in ecological stoichiometric studies to link the elemental composition of individuals and species with their ecological traits, such as drought resistance (related to $\mathrm{K}$ ), light environment (related to $\mathrm{Mg}$ ), or the levels of $\mathrm{N}$ and $\mathrm{S}$ deposition (related to $\mathrm{K}, \mathrm{Ca}, \mathrm{Mg}$, and $\mathrm{S}$; Sardans et al. 2011,

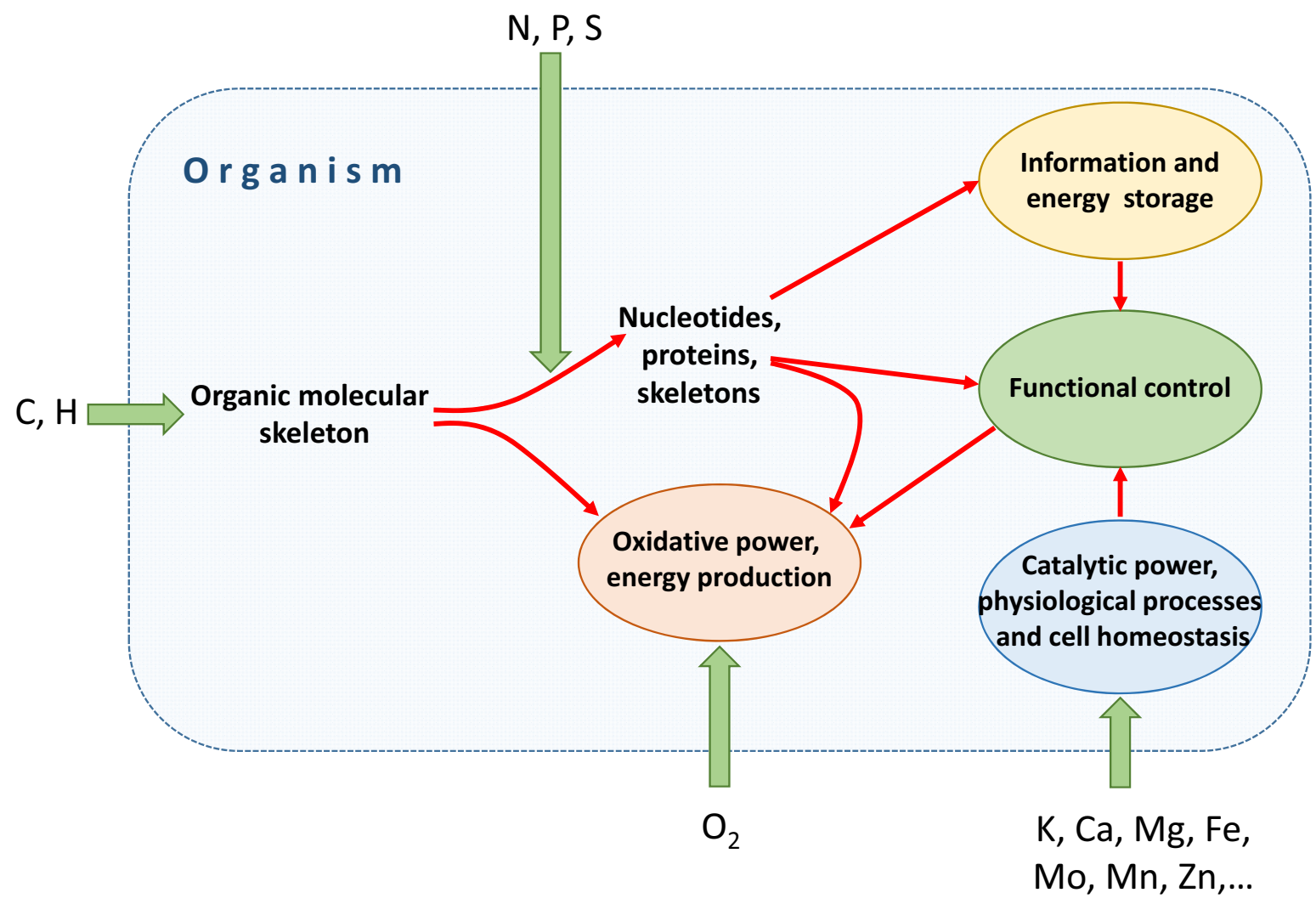

FIG. 1. Schematic of the use of bioelements by organism in different functions. $\mathrm{C}, \mathrm{H}$, and $\mathrm{O}$ are the basis of organismic structure, whereas N, P, and S enter in the various biomolecules allowing biochemical reactions. The molecules that control life processes (e.g., RUBISCO or chlorophyll), that carry information (e.g., DNA and RNA), and that control the storage and release of energy when and where necessary (e.g., ATP and NAD) all incorporate N, P, and, in lower amounts, S. Other bioelements normally present in low concentrations such as potassium $(\mathrm{K})$, magnesium $(\mathrm{Mg})$, iron $(\mathrm{Fe})$, calcium $(\mathrm{Ca})$, molybdenum $(\mathrm{Mo})$, manganese $(\mathrm{Mn})$, and zinc $(\mathrm{Zn})$ are cofactors in catalytic reactions in several biochemical and physiological processes including, for example, photosynthesis, respiration, or cellular ion balance. The arrows indicate the processes in which each bioelement is involved. Green arrows indicate the main organismal functions to which each bioelement contributes. The red arrows indicate the relationships of the different bio-molecules with basic organismal structures and functions. 
2012a, 2015). All of these bioelements should thus be considered in ecological stoichiometric studies.

\section{Elementome AND BiogeochemicAl Niche}

Species use these bioelements to different degrees based on their ecological strategy (example for plants in Fig. 2). Classic Hutchinson's (1957) description of species niche has been largely applied to the main taxa from the point of view of distinct species in a site position in an "n-dimensional hypervolume" formed by the values of determined environmental variables and/or organism traits. For instance, plant species have been classified in a hypervolume formed by three axes, i.e., corresponding to Grime's three strategies: competitor, stress tolerant, and ruderal (Grime 1977). In animals, the species-specific niche has been determined and located in functions of hypervolumes for $n$ axes of different values of energy expenditure (Wilson et al. 2011), distinct diet sources (Bearhop et al. 2004, Araujo et al. 2007), or different elemental composition (González et al. 2017, González et al. 2018). In microbial communities, genotype-niches have also been described in function of the different availabilities of different nutrients (Pereira and Berry 2017) or as a function of the values of diverse functional traits (Lennon et al. 2012) thus describing multivariant spaces with a determined combination of nutrients availability or functional traits where a determined genotype can exist. Any living species should thus tend to optimize its overall function within a determined and space within this volume generated by a combination of these axes describing strategies or biotic and/or abiotic variables while avoiding the overlap with other coexisting species. Following this niche approach, we can hypothesize that distinct species have different functions and life strategies and have therefore developed distinct structures and adopted a certain combination of metabolic and physiological processes. Therefore, each species (of all taxa types) also has different requirements for each bioelement, and should thus tend to have its own elemental composition (Kattge et al. 2011, Yu et al. 2011, Sardans and Peñuelas 2013, 2014, Sardans et al. 2015, Pierce et al. 2016, Bartrons et al. 2018).

We postulate that the more functionally separated two species are, the more different the content of bioelements should be. This led us to propose a "biogeochemical niche" (BN) defined as the multidimensional space defined by the concentrations of bioelements in individuals of a given species (Peñuelas et al. 2008). This BN has been used in the recent years by other authors such as González et al. (2017) who proposed the "multidimensional stoichiometric niche" as the specific position of different taxonomic/trophic groups in the threedimensional space determined by $\mathrm{C}, \mathrm{N}$, and $\mathrm{P}$, and other elements as additional axes in their application of the BN to animals (Gonzalez et al. 2018), as previously proposed for plants by Peñuelas et al. (2008), and for plants and animals together by Bartrons et al. (2018). BN is thus based on the species-specific needs and use of bioelements in different amounts and proportions resulting from the organismic structure and function in the given abiotic and biotic environmental space where the

The example of plants

\begin{tabular}{|c|c|c|c|c|c|c|c|c|c|c|c|}
\hline & \multirow[b]{2}{*}{$\begin{array}{l}\text { Ecological } \\
\text { strategy }\end{array}$} & \multicolumn{5}{|c|}{$\begin{array}{c}\text { Ecological variables } \\
\end{array}$} & \multicolumn{5}{|c|}{ Stoichiometry traits } \\
\hline & & Live-span & \begin{tabular}{|c|}
$\begin{array}{c}\text { Growth } \\
\text { rate }\end{array}$ \\
\end{tabular} & \begin{tabular}{|c|}
$\begin{array}{c}\text { Body } \\
\text { size }\end{array}$ \\
\end{tabular} & \begin{tabular}{|c|}
$\begin{array}{c}\text { Reproductive } \\
\text { strategy }\end{array}$ \\
\end{tabular} & Other & $\begin{array}{c}\begin{array}{c}\text { Stoichiometry } \\
\text { flexibility }\end{array} \\
\end{array}$ & {$[\mathrm{C}]$} & {$[N]$} & {$[P]$} & {$[\mathrm{K}]$} \\
\hline $7=$ & $\begin{array}{l}\text { K-strategy } \\
\text { (competitor) }\end{array}$ & Long & Medium & Large & $\begin{array}{l}\text { Few seeds but } \\
\text { with highly } \\
\text { caloric reserves }\end{array}$ & $\begin{array}{c}\text { Strong } \\
\text { investment } \\
\text { in structure }\end{array}$ & Medium & - & $\uparrow$ & $\uparrow$ & 一 \\
\hline & $\begin{array}{l}\text { A-strategy } \\
\text { (stress- } \\
\text { tolerator) }\end{array}$ & Medium & Slow & $\begin{array}{l}\text { Medium } \\
\text {-small }\end{array}$ & Medium & $\begin{array}{c}\text { Strong } \\
\text { investment } \\
\text { in C-rich } \\
\text { secondary } \\
\text { compounds }\end{array}$ & Low & $\uparrow$ & $\downarrow$ & $\downarrow$ & $\uparrow$ \\
\hline 해셀 & $\begin{array}{l}\text { r-strategy } \\
\text { (ruderal) }\end{array}$ & Short & Fast & Small & $\begin{array}{c}\text { Many seeds but } \\
\text { with low caloric } \\
\text { reserves }\end{array}$ & \begin{tabular}{|c|} 
General \\
trend to \\
develop \\
belowground \\
vegetative and \\
reproductive \\
structures
\end{tabular} & High & 一 & $\uparrow$ & $\uparrow \uparrow$ & 一 \\
\hline
\end{tabular}

FIG. 2. The example of plants. Hypothesized asymmetric uses of bioelements in evolution, depending on the ecological strategy of each species. Vertical arrows indicate low or high concentration values (double arrows indicate especially high values). Dashes indicate not clear patterns. There is a different use of all these elements depending on the ecological strategy of each species (Grime 1977). 
species has evolved (Peñuelas et al. 2008, 2010). Each species should thus have an optimal (at maximum fitness) equilibrium of bioelemental composition, resulting from its functional and structural adaptations, equivalent to the optimum "elemental phenotype" (Jeyasingh et al. 2014). Thus the BN represents the species-specific strategies of growth and resource uptake and the differences in soil-space occupation.

We propose that the processes underlying this speciesspecific elementome and the $\mathrm{BN}$ are based on three basic complementary rules (Fig. 3). First, distinct taxonomic groups exhibit different elementomes, with larger differences as taxonomic distance and evolutionary time increase. Second, at equilibrium, coexisting species tend to have distinct elementomes to minimize competitive pressure. Third, trade-offs between adaptation to being competitive in a stable environment vs. being successful in more fluctuating environments cause homeostasis and plasticity differences between species in a continuum of strategies. The BN distances among species should thus be a function of taxonomic difference, sympatry (coexistence), and homeostasis/plasticity and sympatry (Fig. 3). The BN of taxon $i$ is assumed to be the result of its taxonomical evolutionary determination and its capacity to respond to changes in external conditions, which is also partly taxonomically determined. External changes include nutrient availability (including the level of atmospheric $\mathrm{CO}_{2}$ ), changes in growing season duration, disturbance regimes, and, on longer time scales, changes in soil properties. This capacity to respond to environmental changes is, in turn, a function of taxonomy, sympatry, and homeostasis:

$$
\begin{aligned}
\mathrm{BN}_{i}= & \mathrm{BN}_{\text {of }} \operatorname{taxa}_{i}=\text { Elementome }_{i 1-n} \\
& =(\mathrm{C}: \mathrm{N}: \mathrm{P}: \mathrm{K}: \mathrm{S}: \mathrm{Mg}: \mathrm{Ca}: \ldots)_{i 1-n} \\
& =\mathrm{BNtax}_{i}+\frac{\partial \mathrm{BNtax}_{i}}{\partial \mathrm{Env}}=\mathrm{BNtax}_{i} \\
& +f\left(\operatorname{Tax}_{i}, \text { Symp }_{i}, \operatorname{Hom}_{i}\right)
\end{aligned}
$$

where

BNtax $_{i}$ is the biogeochemical niche explained by taxonomy of taxon $i$ (measured in $n$ individuals of taxon i). An $n$-dimensional hypervolume describes the fundamental BN of a species. The domain of this hypervolume function is restricted to a finite region corresponding to the possible values of bioelemental combinations:

$$
\begin{aligned}
\frac{\partial \mathrm{BNtax}_{i}}{\partial \mathrm{Env}}= & \text { Changes in } \mathrm{BNtax}_{i} \text { of taxa } i \\
& \text { explained by environmental changes }
\end{aligned}
$$

$\operatorname{tax}_{i}$ is the taxonomy of taxon $i, \operatorname{symp}_{i}$ is the sympatry of taxon $i$ with other competing taxa $(j)$, and hom $_{i}$ is the elemental homeostasis-plasticity of the taxon $i$

$$
\begin{aligned}
& \mathrm{BN}_{i}=\mathrm{BN}_{\text {of } \operatorname{taxa}_{i}}=\text { Elementome }_{i 1-n}=(\mathrm{C}: \mathrm{N}: \mathrm{P}: \mathrm{K}: \mathrm{S}: \mathrm{Mg}: \mathrm{Ca}: \ldots)_{i 1-n}=\mathrm{BNtax}_{i}+\frac{\partial \mathrm{BNtax}_{i}}{\partial \mathrm{Env}}=\mathrm{BNtax}_{i}+\mathrm{f}\left(\operatorname{Tax}_{i}, \operatorname{Symp}_{i}, \operatorname{Hom}_{i}\right)
\end{aligned}
$$

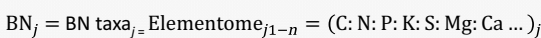

$$
\begin{aligned}
& \mathrm{BN}_{j}=\mathrm{BNtax}_{j}+\frac{\partial \mathrm{BNtax}_{\mathrm{j}}}{\partial \mathrm{Env}}=\mathrm{BNtax}_{j 1-n}+\mathrm{f}\left(\mathrm{Tax}^{j}, \mathrm{Symp}_{j}, \mathrm{Hom}_{j}\right)
\end{aligned}
$$

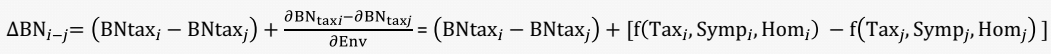

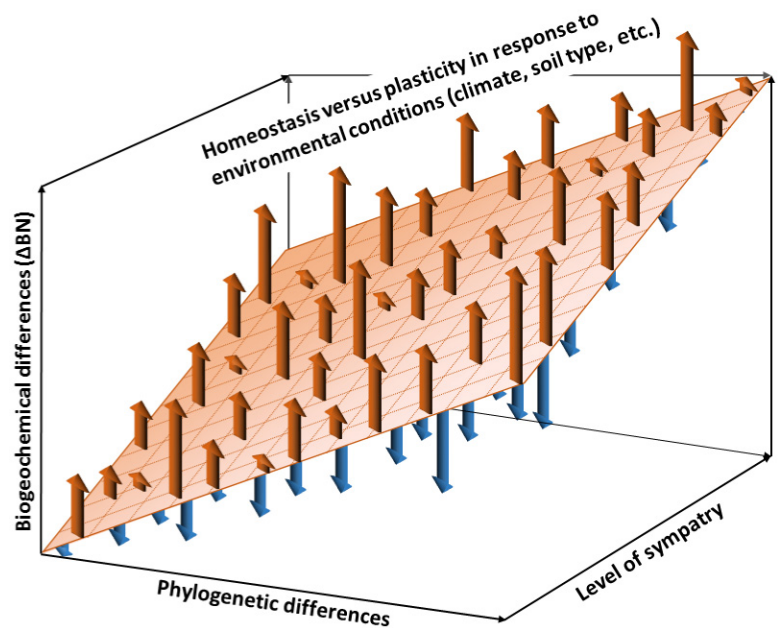

FIG. 3. Theoretical distribution of the biogeochemical differences between species as a function of (1) the taxonomic and phylogenetic distances between them, (2) the level of sympatry (overlap frequency in their corresponding areas of distribution) and (3) the homeostatic or flexible response to current environmental conditions (e.g., climate, soil traits). The surface represents the biogeochemical distance resulting from phylogenetic distance and level of sympatry, and the brown and blue arrows the positive and negative residuals of the biogeochemical niche (BN) distance induced by variable current environmental conditions (e.g., climate, soil traits, neighbors). 


$$
\begin{aligned}
\mathrm{BN}_{j}= & \mathrm{BN} \operatorname{taxa}_{j}=\text { Elementome }_{j 1-n}= \\
& (\mathrm{C}: \mathrm{N}: \mathrm{P}: \mathrm{K}: \mathrm{S}: \mathrm{Mg}: \mathrm{Ca} . .)_{j} \\
\mathrm{BN}_{j}= & \mathrm{BNtax}_{j}+\frac{\partial \mathrm{BNtax}_{j}}{\partial \mathrm{Env}}=\mathrm{BNtax}_{j 1-n} \\
& +f\left(\operatorname{Tax}_{j}, \mathrm{Symp}_{j}, \mathrm{Hom}_{j}\right)
\end{aligned}
$$

The $\mathrm{BN}$ distance between tax $i$ and $j, \Delta \mathrm{BN}_{i-j}$, will be

$$
\begin{aligned}
\Delta \mathrm{BN}_{i-j}= & \left(\mathrm{BNtax}_{i}-\mathrm{BNtax}_{j}\right)+\frac{\partial \mathrm{BN}_{\mathrm{tax} i}-\partial \mathrm{BN}_{\mathrm{tax} j}}{\partial \mathrm{Env}} \\
= & \left(\mathrm{BNtax}_{i}-\mathrm{BNtax}_{j}\right)+\left[f\left(\operatorname{Tax}_{i}, \mathrm{Symp}_{i}, \mathrm{Hom}_{i}\right)\right. \\
& -f\left(\operatorname{Tax}_{j}, \operatorname{Symp}_{j}, \mathrm{Hom}_{j}\right)
\end{aligned}
$$

The segregation of the BNs of the dominant species of a holm-oak evergreen Mediterranean forest (Fig. 4a) and their displacement when exposed to drought in a climatic field experiment (Fig. 4b) constitute a consistent confirmation of these two first BN rules. Very similar results for segregation and displacement were found using different calculation approaches, from the additional use of ratios as explanatory variables to the use of discriminant and other multivariate analyses (Appendix S1: Fig. S1). Pairs of species with more overlap in their distributions had greater differences in their BNs as estimated from PCA scores (PCA based on N, P,
$\mathrm{K}, \mathrm{S}, \mathrm{Ca}$, and $\mathrm{Mg}$ concentrations) in a set of the 12 most representative Mediterranean tree species of South Europe (Fig. 4c), confirming the third rule. The BN hypothesis is an extension of the ecological niche concept (Schoener 1989) to the bioelemental components of life. The BN aims to establish the morphological and functional "adaptation" to the abiotic and biotic traits that define the niche of each species-genotype from simple determination of the elemental composition. It is based on the different contribution of each bioelement to the different organismal functions and structures. Its main advantage over other theoretical classical niche concepts is that it can be characterized by the measurable bioelemental composition, the elementome, of the organism, species, community, or even biome (Fig. 5). This BN measurement is not biased by the most abundant bioelements since the analysis is conducted for a multivariate space defined by the standardized elemental concentrations (Figs. 4 and 6).

The quantitative $\mathrm{BN}$ framework can then be used to improve projections of how species will respond to environmental changes, provided elementome homeostasis/ plasticity (Hom) on a given time horizon is known. This Hom can be defined, for example, as the coefficient of variance of the scores for the different individuals of a species in the PCA. It results from both intraspecific variation and phenotypic individual responses. These two responses can be differentiated when the hypervolume occupied by the individuals of one species is compared with the hypervolume generated after changing
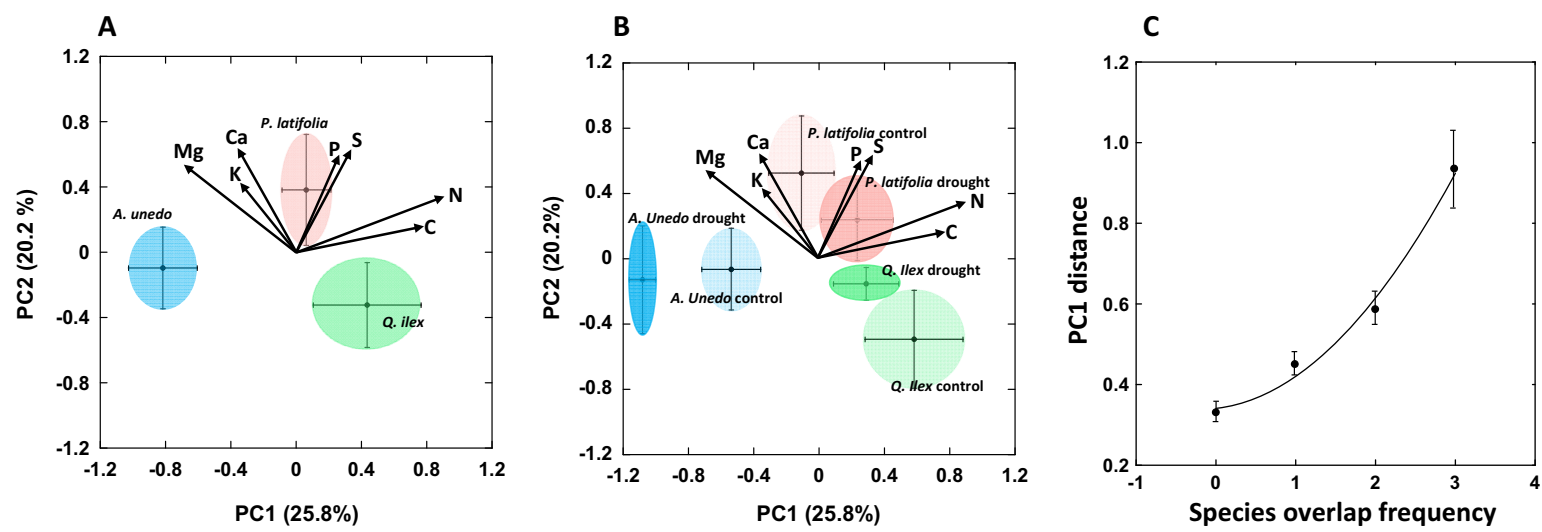

FIG. 4. (A) Biogeochemical niche segregation among coexisting plant species. We analyzed the foliar elementomes of the three dominant trees (Quercus ilexi, Arbutus unedo, and Phillyrea latifolia) in a field experiment of climatic manipulation in an evergreen Mediterranean forest in the Prades Mountains (Catalonia). We plotted the plant scores for the first two principal components of the principal component analysis (PCA) conducted with foliar N, P, K, S, Ca, Mg concentrations as variables. (B) Shifts in biogeochemical niche in a drought experiment. The mean \pm confidence intervals $(95 \%$, represented by the ellipses) of the species $\times$ climate interaction groups are depicted in the plot thus comparing control plants to those submitted to a decrease of $20 \%$ of water availability during $6 \mathrm{yr}$ in field conditions. The other PCAs (from PC3 to PC7) and the corresponding other axes are now shown in the Appendix S1: Table S1. (C) Score distances for PC1 of the PCA of the foliar stoichiometry (foliar N, P, K, S, Ca, and Mg concentrations and their ratios) in a set of the 12 most representative Mediterranean species of South Europe as a function of the frequency of pairwise species overlap (coincidence in the same community): six broadleaf species (Quercus ilex, Q. faginea, Q. pyrenaica, Q. suber, Castanea sativa, and Eucalyptus globulus) and six needleleaf species (Pinus halepensis, P. pinaster, P. nigra, P. pinea, Juniperus oxycedrus, and $J$. thurifera). Numbers represent 0 , no overlap; 1, occasional overlap; 2, moderate overlap; 3, frequent overlap. Based on Rivas-Martínez et al. (2001), De Bolos and Vigo (2001), CREAF, Catalonia cover map, (2013) and Folch et al. (1984). 
the environmental conditions, for instance in experiments in field conditions where environmental conditions are changed.

$\mathrm{BN}$ aims to refocus the use of the hypervolume in ecological niche studies. An $n$-dimensional hypervolume was originally proposed by Hutchinson (1957) and defined as a subset of the space, i.e., an $n$-dimensional geometrical shape, to describe the fundamental niche of a species. Hutchinson suggested that the axes correspond to requirements of the species (e.g., light, temperature, food size) and that the boundaries of the shape indicate the conditions that permit the growth and reproduction of the individuals of a species. This description of the species niche has been widely used and discussed (Chase and Leibold 2003, Begon et al. 2006, Colwell and Rangel 2009, Holt 2009, Peterson 2011). There is now a growing set of statistical methods to operate this hypothesis of species niche with data (Blonder 2017). BN should be a tool to detect the niche shifts at short-, medium- and long-term scales in response to all type of environmental changes (drought, species invasion, pests, new biotic relationships, etc.). The mathematical description of each specific BN position in a multi-space as a function of the concentrations of several bioelements can be done by using essential multivariate statistical analyses such as principal components analyses (PCA) or functional/ general discriminant analysis (F/GDA; Sardans et al. 2015, Urbina et al. 2017), or other analyses such as kernel density estimation, support vector machine, Bayesian ellipse, etc. (Blonder 2017). BN distances and the level of overlap/separation among different groups can be computed with the score means (centroids) of the main axes (in the PCAs; Fig. 4, Appendix S1: Fig. S1) or with squared Mahalanobis distances (in the discriminant analyses; Appendix S1: Fig. S2). These metrics provide numerical evidences of the "distances" between the BN of different species and of the $\mathrm{BN}$ displacement (if any) when comparing the $\mathrm{BN}$ of different populations of the same species along space or time. Correlations between matrices provide a way of comparing the distances between hypervolumes, for instance the correlation matrix of the genome differences or of the differences in some ecological or ecophysiological variables in a particular set of species with the corresponding correlation matrix of the BN distances of the same set of species. Statistical tests such as Mantel tests (Mantel 1967) can be used with this aim. All these mathematical tools to estimate the $\mathrm{BN}$ allow all levels of comparisons, from species (Sardans et al. 2015) to different taxa and trophic groups (Bartrons et al. 2018), also including the comparison of different populations of the same species growing under distinct environmental conditions (Urbina et al. 2015, 2017).

These studies have shown the facility and consistency in the use of different types of multivariate analyses to detect the $\mathrm{BN}$ in spatial and temporal gradients/scales.
Moreover, the different levels of homeostasis/plasticity of different studied groups can be calculated by the area/ volume in that the individuals of each group are spread in the multidimensional space generated. The temporal shifts of the BN of a species or populations of one species can also be calculated and thus their evolution can be followed. BN also allows the description and quantification of niche appearance (i.e., when new species colonize the ecosystem), expansion, contraction, and extinction. Therefore, BN constitutes a quantifiable tool to detect, quantify and thus better comprehend the mechanisms and processes underlying community evolution and species turnover (Fig. 7). Niche construction vs niche expansion or niche contraction vs niche extinction are apparently difficult to differentiate because of their similar outcomes, and niche contraction (and extinction) could be the result of environmental filtering, whereas niche expansion could be due to addition of species to a community. Phenomena within the niche theory such as niche convergence (Pianka et al. 2017) can be followed by monitoring the species $\mathrm{BN}$ hyper-dimension along spatial and temporal gradients and focusing on the changes in the level of overlap/distance in their BN.

\section{EVIDENCE FROM ObSERVATIONAL DATA}

\section{Taxonomy}

The BN hypothesis is supported by strong evidence in recent studies. Observational data (Sardans and Peñuelas 2014, Bartrons et al. 2018) provide evidence that plant and animal species have their own elementome, their own BN. For example, different groups of species in distinct climatic biomes have different foliar bioelemental compositions and stoichiometries (Sardans and Peñuelas 2014, Sardans et al. 2015, 2016a,b, Sardans et al. 2017). Foliar bioelemental composition of forest tree species, for example, has been positively correlated with phylogenetic distance between taxa at different geographic extents, from local to continental (Sardans et al. 2014, 2015, 2016a,b). Bioelemental composition and stoichiometry thus tend to differ more between phylogenetically distant than between phylogenetically close tree species (Sardans and Peñuelas 2014, Sardans et al. 2014, 2015, 2016a,b). These positive correlations between elemental composition differences and phylogenetic distances have been also observed in animals (Gonzalez et al. 2018) in a further demonstration of the first process underlying the $\mathrm{BN}$ hypothesis. The stoichiometry of an individual under a given climatic and edaphic condition is determined in part by the uptake and the efficiency with which the individual uses each bioelement, all of which depend on the trade-offs among the various individual functions that maximize individual fitness under that specific climatic situation. Each species and taxon have its own space in the two-dimensional plot formed by the first two components of the PCA of individual composition $(\mathrm{N}, \mathrm{P}, \mathrm{S}, \mathrm{K}, \mathrm{Ca}$, and $\mathrm{Mg}$ 

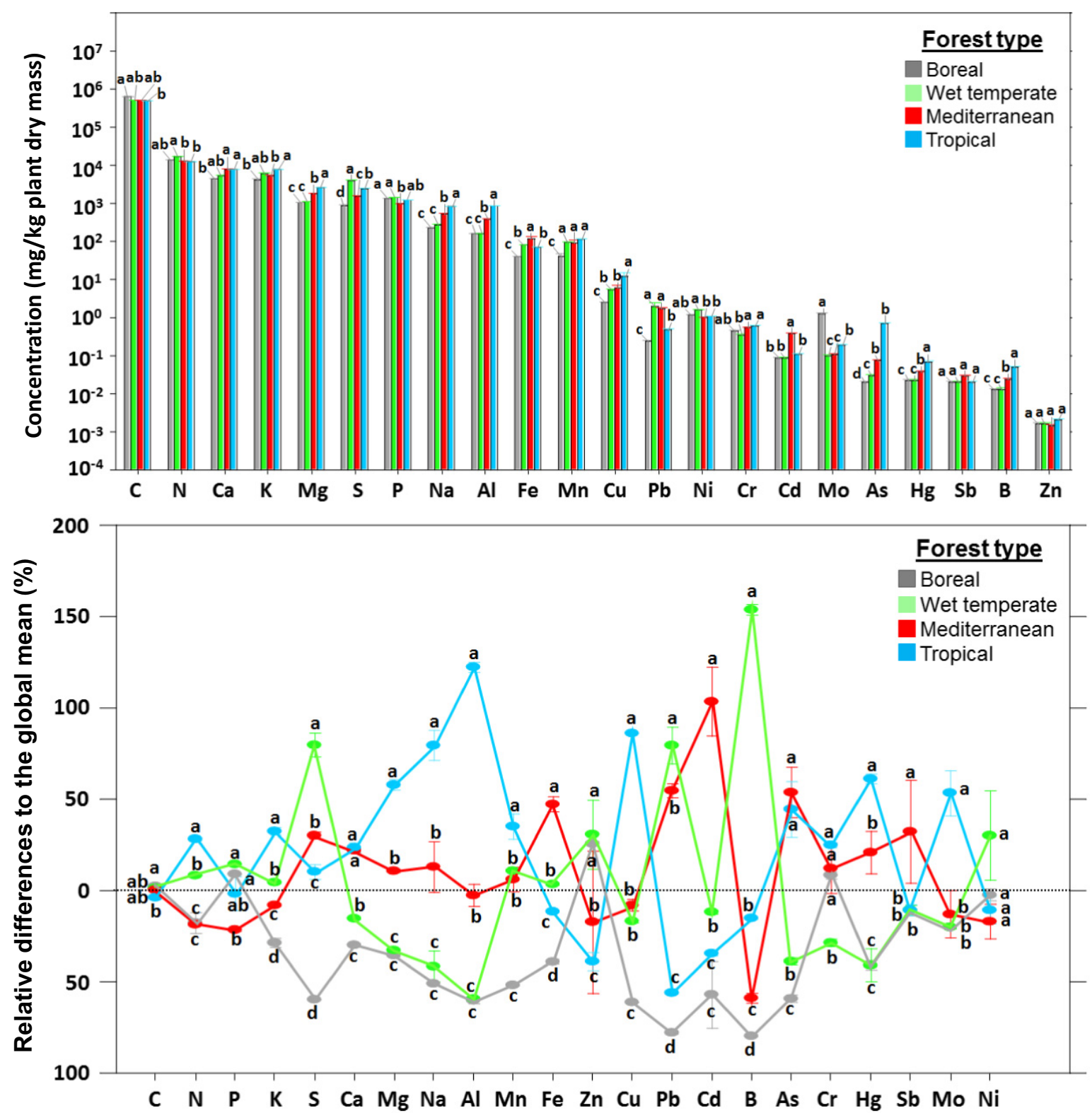

FIG. 5. Elementome, full spectrum of bioelemental content, of boreal, wet temperate, Mediterranean and tropical forests. (A) Elementomes calculated from web of science data incorporated to our GEU-CREAF data set (boreal forest, 473 sites and 1,890 trees; wet temperate forests, 2,882 sites and 12,665 trees; Mediterranean forests, 2,001 sites and 2,901 trees; tropical wet forest, 1,100 sites and 1,821 trees). The values in panel B show the difference of each forest type relative to the global mean ( \pm SE). We have used data from the main available databases (e.g., TRY and ICP forest) and from an exhaustive search for woody plants from nonmanipulated areas in WEB of Science. Different letters indicate significant differences $(P<0.05)$.

concentrations and their ratios; see example in Fig. 4a and see Appendix S1: Table S1 for the scores of additional PCs).

\section{Sympatry}

Larger differences in the stoichiometry of foliar composition among sympatric than allopatric species have recently been reported both in plant communities
(Sardans et al. 2015, 2016a,b) and in animal communities (Gonzalez et al. 2018) as implied in the third process involved in the $\mathrm{BN}$. The overlapping frequency of all pairwise comparisons among many tree species is correlated with the elementome distances of the corresponding tree pairs (Fig. 4c; Sardans et al. 2015), thus supporting this third process. Different grass and shrub species growing under different climatic conditions in communities with distinct species compositions maintain 


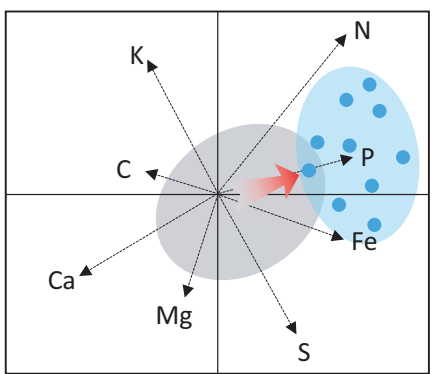

Biogeochemical niche

Displacement

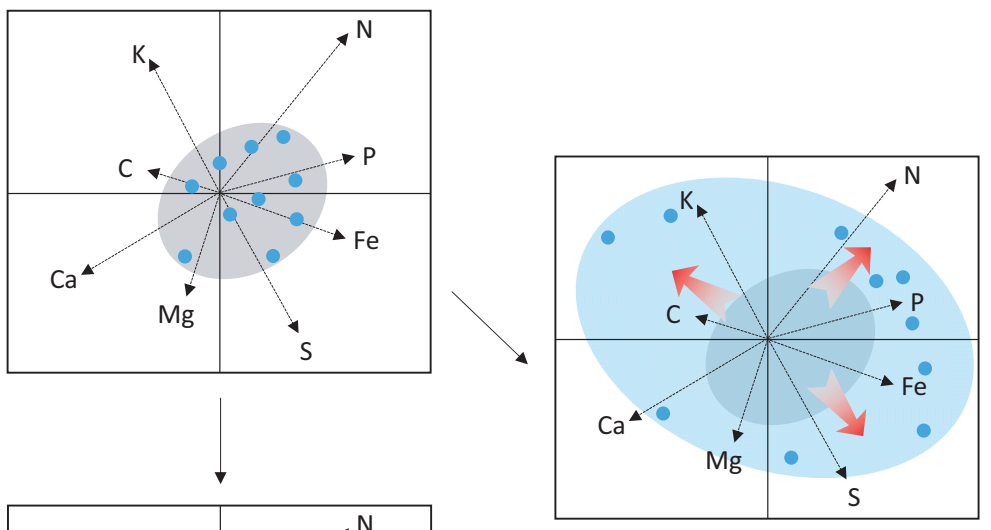

Biogeochemical

Expansion

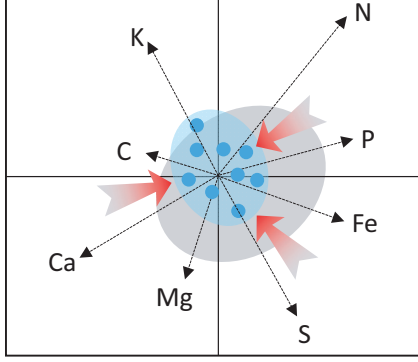

Biogeochemical niche

Concentration

FIG. 6. Three possible biogeochemical niche responses to short-term changes in the environmental conditions: contraction, expansion, or displacement. Blue dots represent individuals of a species, gray and blue ellipses represent the initial and final BN space.

distinct species-specific foliar compositions, although there may be displacement, expansion or concentration of the biogeochemical space occupied (Fig. 6) depending on the coexisting species (Urbina et al. 2015, 2017). The species bioelemental composition changes in parallel with the shifts of environmental conditions, in accordance with the new optimal functions that require new proportional use of different bioelements. Contraction, expansion, and displacement in the short term would thus be complemented by construction (allopatric speciation), extinction, segregation, and equalization in the long-term both for estenoic (narrow range of ecological and environmental conditions) and euroic (wide range) niches (Fig. 7).

In-depth investigation of these processes constitutes a challenge for ecologists. Some studies have already demonstrated different biogeochemical niche space (euroic-estenoic) among different coexisting species-genotypes in plants (Sardans et al. 2015, Urbina et al. 2015, 2017), animals (González et al. 2017, 2018, Bartrons et al. 2018) and microbes (Pereira and Berry 2017). Other studies have observed how the same species displaced their biogeochemical niche depending on the intraspecific and intraspecific competition (Urbina et al. 2015, 2017, Sardans et al. 2016a,b). However, observational field studies along successional stages and field manipulation studies of biotic (introducing new species, changes in density, and so on), and abiotic (changing climate conditions or nutrient availability) factors in conjunction with similar studies in greenhouse, microcosm, and mesocosm conditions would be necessary to further test the consistency of the new holistic view of ecosystem processes provided by the $\mathrm{BN}$.

\section{Homeostasis/plasticity}

Changes in environmental supply (for example soil or water bioelemental composition) can affect the bioelemental composition of organisms, as observed in microbes (Frenken et al. 2017) and plants (He et al. 2016, Salvagiotti et al. 2017). A trade-off between adaptations to be competitive in stable environments vs. being successful in less stable environments should underpin the differences in the continuum of homeostasis-plasticity strategies in bioelemental composition and stoichiometry among individuals, species and communities (Figs. 3, 4b). Higher $\mathrm{N}$ and $\mathrm{P}$ concentrations and lower N:P ratios coincide with higher stoichiometric plasticity in opportunistic ( $\mathrm{r}$-strategy) than in competitor (K-strategy) plant species (Yu et al. 2011). Climate can also account for some of the variability in the bioelemental composition of plant tissues at intra- and interspecific levels (Sardans et al. 2015, Sardans et al. 2016, Zhang et al. 2012) indirectly though climate controls on bioelemental availability and directly as a forcing of traits linked to the elementome. Environments with 


\section{Biogeochemichal niches defined by the different elementomes}

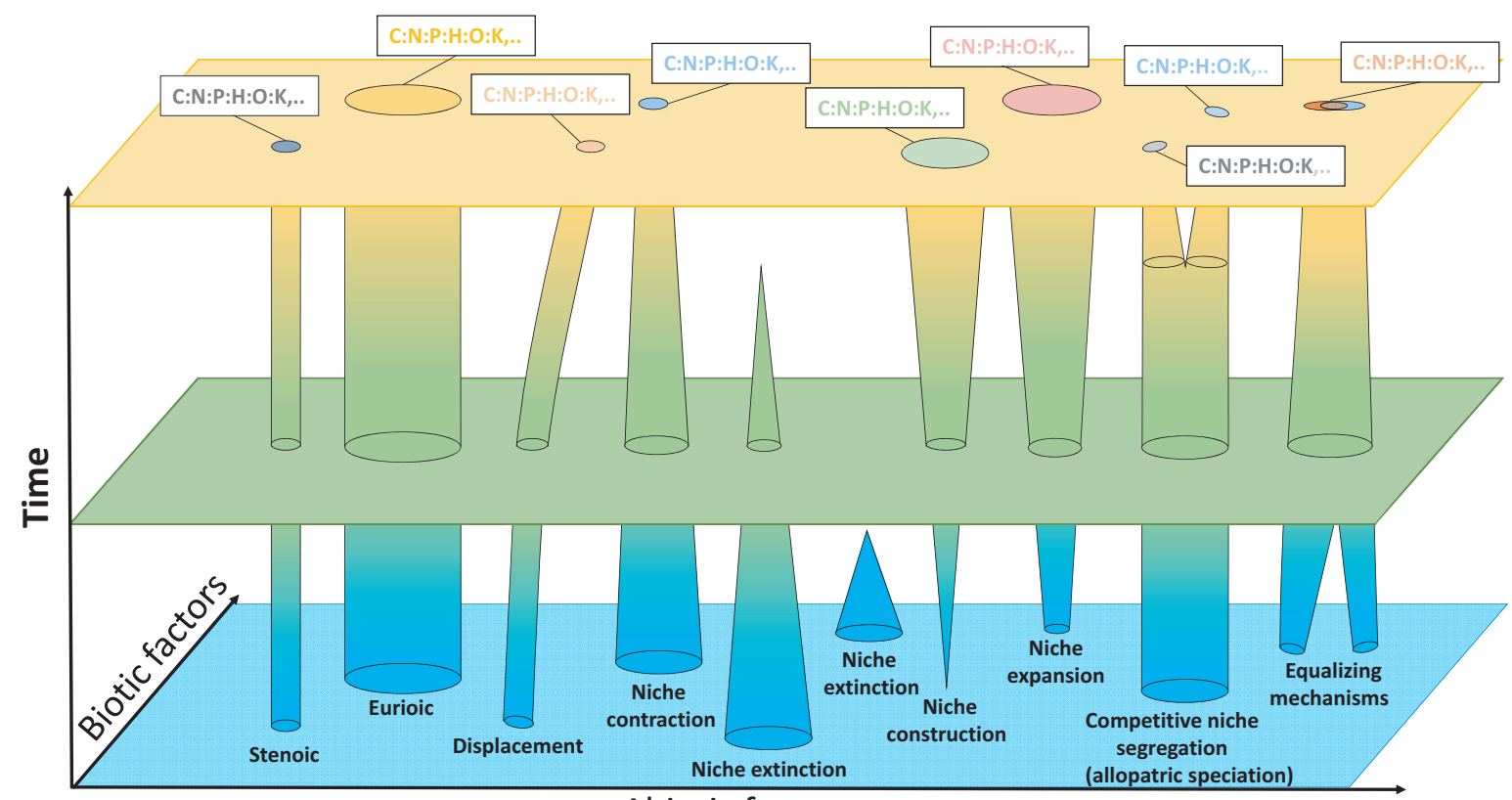

Abiotic factors

FIG. 7. Possible responses of species biogeochemical niches to long-term changes in the abiotic and biotic environmental conditions (possible evolutionary changes in the elementome of a species). We hypothesize that each species has an optimal function related with its niche traits and thus an optimal content of bioelements. Species have an optimal function related with its niche traits and thus an optimal content of bioelements. The species content of bioelements changes in parallel with the species niche shifts according with the new optimal functions for the new environmental conditions. Contraction, expansion, and displacement are here complemented by construction (allopatric speciation), extinction, segregation, and equalization at the long-term both for estenoic (narrow range of ecological and environmental conditions) and euroic (wide range) niches. The communities resulting of interactions with changing abiotic and biotic conditions are even more capable to adjust their stoichiometry than single species to new nutrient supply and stoichiometrical conditions. Each particular niche constitutes a singular functional and physical position in the ecosystem that can vary with time in response to changes in abiotic variables (climate, perturbations such as volcanic eruptions, etc.) and to changes in the impacts and feed-backs of the other organisms living in it (biotic factors). In this context, each niche should determine a specific and particular content of different bioelements in each moment. This should also determine a singular elementome accompanying the niche characteristics of each genotype and species at both micro- and macro-evolutionary timescales.

fluctuating nutrient availabilities relative to the species' lifetime would have to favor organisms with greater stoichiometric plasticity. Stoichiometric plasticity tends to decrease in response to fertilization as environmental nutrient richness increases, in both terrestrial and aquatic systems (Sistla et al. 2015), thus suggesting a different position in the homeostatic-plasticity continuum between species in nutrient-rich vs. nutrient-poor environments. The $\mathrm{BN}$ hypothesis allows to detect the plasticity at two levels: at the individual level (phenotypic plasticity) by showing how its individual elemental composition can vary when environmental conditions shift, and at the intraspecific level as a result of intraspecific variability (individual genotypic differences, different ontogenic stage, sex differences, and so on) in elemental composition of a set of individuals of the same species living under the same environmental conditions. This dual source of variability due to natural intra-population variability and to individual capacity to shift $\mathrm{BN}$ in response to environmental changes can be at least partially detected experimentally with multivariate analyses working with populations of the same genotype growing in different environmental conditions across space or time.

\section{Evolutionary change}

Species have stoichiometric strategies to adapt to heterogeneous environments (Sun et al. 2017) and are able to adapt their elemental compositions to those of the media after several generations (Turner et al. 2017). The stoichiometry of phytoplankton appears to reflect oceanic stoichiometry over geological timescales, providing even stronger support to this link between organisms' composition and media nutrients availability (Quigg et al. 2003, Reinhard et al. 2017). Other studies of terrestrial ecosystems found that microbial community N:P ratios were correlated with plant-community and soil N:P ratios (Kerkhoff and Enquist 2006, Cleveland and Liptzin 2007). Close relationships between 
microbial and soil C:N ratios across a soil C: $\mathrm{N}$ gradient have been also observed, e.g., in Scandinavian boreal forests (Högberg et al. 2006). Evidence suggests that variation in the environmental supply of $\mathrm{P}$ affects the expression of highly conserved genes (e.g., those of the phosphate-transporter system) and that the acquisition, assimilation, and allocation of $\mathrm{P}$ is genetically variable (Jeyasingh and Weider 2007). Transcriptomic studies of algae (Grossman 2000), microbes (Baek and Lee 2007), terrestrial plants (Morcuende et al. 2007), and more recently herbivores (Jeyasingh et al. 2011) have also reported that the availability of $\mathrm{P}$ influences genetic expression. Such effects of the supply of $\mathrm{P}$ should impinge on fitness and drive evolutionary change. Jeyasingh et al. (2009) observed that genetic variation in phosphoglucose isomerase $(\mathrm{Pg})$ indicated that $\mathrm{Pg}$ heterozygotes of Daphnia pulicaria outcompeted Pg homozygotes under conditions of low C:P ratios, whereas the opposite was observed under conditions of high C:P ratios.

Availability and stoichiometry of bioelements can determine transcriptional expression and metabolomic structure (Rivas-Ubach et al. 2012) and phenotypic selection (Chowdhury et al. 2015), and can affect genomes and thereby become evolutionary drivers for organisms and ecosystems on the longest timescales (Acquisti et al. 2009). For example, the mechanisms controlling $\mathrm{P}$ acquisition are genetically variable, and the expression of the genes involved is strongly affected by its environmental supply (Grossman 2000, Jeyasingh and Weider 2007, Jeyasingh et al. 2011, 2014). Selection in environments with very low $\mathrm{N}$ availability can even favor new genes richer in N-poor nucleotides (Acquisti et al. 2009). Evolution could also be controlled by directly affecting the quality of matter, e.g., different N:P ratios available to genomes for the optimal allocation of $\mathrm{N}$ and $\mathrm{P}$ to DNA/RNA for maximizing fitness (Sardans et al. 2012b).

\section{BN of communities}

Communities should be more capable to adjust their stoichiometry to additional nutrient inputs and varying stoichiometrical conditions than single species (Danger et al. 2008). A simple and comprehensive example, only considering $\mathrm{N}$ and $\mathrm{P}$ concentrations and stoichiometry, can be observed when $\mathrm{P}$ is added to a freshwater community. In such a case, a shift in community composition typically occurs in favor of $\mathrm{N}$-fixing organisms with a posterior cascade of composition changes towards a new equilibrium in community composition (Davidson and Howarth 2007). Environmental changes (anthropogenic or natural) such as perturbations or shifts in climate, $\mathrm{N}$ deposition, species invasion, or the increase in atmospheric $\mathrm{CO}_{2}$ can probably generate changes in the availability of various nutrients. Species of the target community can then adapt, depending on their phenotypic flexibility. For example, species with a $\mathrm{BN}$ better adapted to new environmental conditions can be favored under large long-term loadings of $\mathrm{N}$ by $\mathrm{N}$ deposition, but species less well adapted can disappear. Species can also turnover, when possible, with the entrance of new species with traits better adapted to life in the newly generated niches (with different optimal elemental compositions). This sequence of events has been observed in several field studies where shifts in the elemental composition of the media (water or soil) due to changing conditions (anthropogenic or natural) have been translated into changes in the species composition of species of the community (Sterner and Elser 2002). The species with more favorable elemental compositions gain then importance and/or there is species turnover (Novotny et al. 2007, Yu et al. 2011, Poxleitner et al. 2016, Du 2017). Changes in N:P have been related to substantial changes in species composition of plant communities (Peñuelas et al. 2013) and changes in P loads to adjusted C:P ratios in zooplankton communities (Teurlincx et al., 2017).

\section{FEedBacks on EnVIRONMENT}

The relationships between evolution and the bioelemental composition of ecosystems are bidirectional, because nutrient supply can affect evolutionary processes, while the changes imposed by evolutionary processes can also affect nutrient supply (Durston and El-Sabaawi 2017). As a result, ocean and soil stoichiometries may have been also partly controlled by organisms over long time scales (Tyrrell 1999, Lenton and Klausmeier 2007, Hatton et al. 2015, Zederer et al. 2017).

The strongest support of Redfield ratio comes from the fact that the N:P ratio in the open sea areas of all major oceans is remarkably similar to the $\mathrm{N}: \mathrm{P}$ ratio of plankton (16:1). This is due to the residence time of $\mathrm{N}$ and $\mathrm{P}$ in the ocean (104 years) relative to the ocean's circulation time (103 years; Falkowski and Davis 2004). However, in addition to the geochemical causes, biological processes are also underlying Redfield ratios. $\mathrm{N}_{2}$ fixation can play an important role in ocean $\mathrm{N}: \mathrm{P}$ ratio homeostasis (Tyrrell 1999, Lenton and Watson 2000, Ganeshram et al. 2002, Kenesi et al. 2009). When ocean $\mathrm{N}: \mathrm{P}$ ratios fall too low, nitrogen fixation increases by augmenting the biomass of $\mathrm{N}_{2}$-fixers and when these $\mathrm{N}_{2}$-fixers decompose or are eaten, their $\mathrm{N}$ rich organic matter turns to dissolved ammonium and nitrate in the water increasing water N:P ratios. Conversely, when the ratio rises too high, $\mathrm{N}_{2}$ fixation inputs decrease by $\mathrm{P}$ limitation of $\mathrm{N}_{2}$-fixation, thus restoring lower water $\mathrm{N}: \mathrm{P}$ ratio. This process would confer to $\mathrm{P}$ primary control of ocean production (Tyrrell 1999, Lenton and Klausmeier 2007).

Soil elemental composition is also controlled by the species of plants (Zederer et al. 2017), the soil microbiota (Hartman et al. 2017), and the interactions between plants and soil fungal communities. For example, Quercus species control nutrient dynamics by 
determining the composition and activity of the forest floor fungal community (Chávez-Vergara et al. 2016) and the litter type (Hatton et al. 2015). Conifers acidifying soil to reduce soil nutrient availabilities (base cations and $\mathrm{P}$ ) to outcompete species with a different $\mathrm{BN}$ provide another consistent example.

We should thus expect a constant feedback between organisms and their environment. Understanding the processes underlying species shifts in bioelemental composition and their genetic basis will help us understand the responses of organisms to environmental changes (Yamamichi et al. 2015, Leal et al. 2017) and in turn the effects of organisms on ecosystem functioning and services (Frisch et al. 2014, Leal et al. 2017). We are currently still moving towards understanding and identifying the feedbacks between species evolution and shifts in the bioelemental composition of ecosystems and how these feedbacks interact and determine ecosystem and evolutionary processes. Available data seem to indicate that the long-term availability and use of bioelements can determine individual selection and therefore ecosystem function and organization and evolution of life.

\section{The Biogeochemical Niche Hypothesis and Related APPROACHES}

Functional traits such as leaf mass area, seed size or plant height have been also used to build hypervolumes to identify species-specific niche (Violle and Jiang 2009, Lamanna et al. 2014, Violle et al. 2014). However, taxonomical groups (e.g., animals, plants, fungi) have different functional traits, preventing the use of these approaches to different taxonomy clades. Instead, all the organisms, independently of their taxonomical groups, are constituted by the same basic bio-elements, thus providing a general and easy to measure variable, the elementome, with which to establish the species-specific niche in plants (Sardans et al. 2015), in animals (González et al. 2017), and in sets of plants and animals analyzed altogether (Bartrons et al. 2018). The use of organismal elemental stoichiometry has been proven to be related to the species functional traits in aquatic and terrestrial ecosystems (Sardans et al. 2012c, Peñuelas et al. 2013, Meunier et al. 2017). This also allows us to establish relationships between observed shifts in ecosystem N:P medium (water or soil) with the shift in species dominance or community and/or in trophic web composition and structure.

We first defined the BN in 2008 for plant communities (Peñuelas et al. 2008) and we have since then developed it in several papers (Peñuelas et al. 2008, Sardans and Peñuelas 2014, Frisch et al. 2014, Sardans et al. 2015, Sardans et al. 2016, Urbina et al. 2017). Other groups have also used this approach (De and Bhattacharyya 2009, Menge and Hedin 2009, Chimphango et al. 2015, Zamora et al. 2017), obtaining results that have provided solid experimental consistency to $\mathrm{BN}$ hypothesis. The BN that we define as species elemental composition is wide in scope and simple in determination, and reflects the structure and function of each species-genotype resulting from its unique evolutionary history (Sardans et al. 2008a,b,c 2015, Urbina et al. 2017).

$\mathrm{BN}$ aimed to progress beyond the classical ecological stoichiometric studies (Elser et al. 2000a,b, 2009, 2010, Sterner and Elser 2002, Elser and Kyle 2009, RivasUbach et al. 2012, Sardans et al. 2012b). These ecological stoichiometric studies have linked several important ecosystem processes with ecosystem and organismal C:N: $\mathrm{P}$ ratios. Several organismal functions and responses to environmental shifts, though, cannot be explained only by the changes in these three main bioelements (Sardans et al. 2012b,c). As stated above, other bioelements (such as $\mathrm{K}, \mathrm{S}, \mathrm{Ca}, \mathrm{Mg}$, and $\mathrm{Fe}$ ) are needed in ecological stoichiometric studies to provide more complete and global information correlating shifts in organismal elemental composition with changes in organismal morphology and function in response to environmental conditions (Peñuelas et al. 2008, Peñuelas and Sardans 2009, Sardans and Peñuelas 2014, Sardans et al. 2015). The BN hypothesis is thus based on the entire elemental composition or at least on the composition of as many elements as possible. The $\mathrm{BN}$ hypothesis has afterwards also been used to refer to the concentrations and availabilities of nutrients in soil or water that favor or determine the corresponding spatial occupation by a species or taxon (De and Bhattacharyya 2009, Menge and Hedin 2009, Chimphango et al. 2015, Zamora et al. 2017).

A similar hypothesis of a "multidimensional stoichiometric niche" was recently introduced by Gonzalez et al. (2018). These authors defined a "multidimensional stoichiometric niche" for taxonomic/trophic groups as their position in the three-dimensional space determined by $\mathrm{C}$, N, and P following Peñuelas et al. (2008). González et al. (2017) also interestingly opened the possibility to incorporate more elements, and also element fluxes and transformation rates as additional axes. In their studies, Gonzalez et al. (2018) proved the suitability of this approach for animals. This "multidimensional stoichiometric niche" also tried to incorporate rates of nutrient cycling, but these are much more difficult to quantify than elemental concentrations and ratios. Thus, according with the observations in plants, animals, microbes, and also in combination of different taxa altogether (animals and plants; Peñuelas et al. 2008, Sardans et al. 2015, González et al. 2017, Bartrons et al. 2018), the BN multidimensional space proposed here should allow the establishment and quantification of the links between the species BN distances and their taxonomic/phylogenetic distances and between homeostatic capacities and sympatries, and thus to provide information on species/taxa evolutionary processes. The BN thus also aims to refocus the use of the hypervolume in ecological and evolutionary niche studies as discussed above in the section of "Elementome and Biogeochemical Niche".

Another similar approach to $\mathrm{BN}$, ionomics, i.e., the profiles of mineral elements in plants, has been proposed mostly focused on the genetics of plant mineral nutrition. Ionomics analyzes the elemental composition of 
organisms in relation to soil concentrations of nutrients and trace elements and also plant functional traits (Salt et al. 2008, Buescher et al. 2010, Baxter et al. 2012, Huang and Salt 2016). Ionomics is mostly used to study the content of bioelements with electrical charge, mostly absorbed from soils, and mostly within a context of the impact on plant health, food quality and/or identification of hyper-accumulation species. It comes from the confluence of metabolomics and plant nutrition (Salt et al. 2008) that, with the incorporation of modern analytical platforms such as ICP techniques, allows us to determine most elements altogether. The fusion of this information with bioinformatics and genetic tools, such as genomic sequencing, allows the identification of the genes that control uptake, storage, and use of soil nutrients and trace elements in plants (Baxter et al. 2012, Lowry et al. 2012). This further allows us to analyze the effects of genes and environment on plant nutrition (Neugebauer et al. 2008, Buescher et al. 2010, Lowry et al. 2012) and plant physiological status (Baxter et al. 2008). BN instead considers all, or as many as possible, bioelements, i.e., also including those such as $\mathrm{C}$ or $\mathrm{N}$ that are initially from atmospheric, not ionic, forms (e.g., $\mathrm{N}$ comes mainly from atmospheric $\mathrm{N}_{2}$; nitrates are rare in bedrock). $\mathrm{BN}$ focuses on organisms and on the total elemental composition and stoichiometry as a proxy of their optimal function and morphology, whereas ionomics focuses on the composition of the medium (soil) to describe different ionomic niches in the abiotic dimension of an ecosystem. Ionomics has aimed to explain shifts in ionic composition by identifying specific genes and their control in changing environmental conditions, thus providing knowledge and information to improve the nutrition of crop species. BN is instead based on the idea that the entire genome of each genotype/species determines species-specific functionality and morphology (more distinct as genomic differences increase) and thus a distinct use of different bioelements, which in turn contribute asymmetrically to different functions and morphological structures. BN can thus be used without knowing about the control of gene expression or about gene function. Moreover, whereas ionomic approach has been developed for plants, BN is developed to be equally applicable to all type of taxa.

Even though these ionomic studies are mostly agriculturally oriented, and thus the link with the classical theory of ecological niche is not specifically considered, they are consistent with the BN hypothesis, at least at the level to correlate elemental composition with phylogenetic distance. They constitute strong evidence in favor of $\mathrm{BN}$ consistency and constitute a very interesting contribution to the $\mathrm{BN}$.

\section{Concluding Summary and Perspectives}

Here we propose a BN of genotypes/species/communities that should provide an improved and quantifiable proxy of the general ecological niche. The $\mathrm{BN}$ is characterized by a particular hypervolume of their individual elementomes based on their specific needs and use of bioelements in different amounts and proportions for their structure and functioning. Several organismal structures and functions and the responses to environmental shifts cannot be explained only by the changes in the three main bioelements, $\mathrm{C}, \mathrm{N}$ and $\mathrm{P}$. We propose that other bioelements such as $\mathrm{K}, \mathrm{S}, \mathrm{Ca}, \mathrm{Mg}, \mathrm{Fe}, \mathrm{Mn}$, and Mo, among others, must be incorporated to fully describe the $\mathrm{BN}$. The $\mathrm{BN}$ extends the classical ecological niche concept but has the advantage that it can be easily, directly and quantitatively analyzed.

The biogeochemical distances, i.e., the differences in elementome, among species, are a function of taxonomy (phylogenetic distance), sympatry (the bioelemental compositions should differ more among coexisting than among non-coexisting species to avoid competitive pressure), and homeostasis (within the continuum between high homeostasis/low plasticity and low homeostasis/ high plasticity). Further studies are warranted to discern the ecological and evolutionary processes involved in the $\mathrm{BN}$ of all types of individuals, taxa, and ecosystems. The changes in bioelemental availability and use at long timescales should determine phenotypic selection and therefore also ecosystem function and organization, and, at the end, the evolution of life and the environment.

\section{ACKNOWLEDGMENTS}

The authors would like to acknowledge the financial support from the European Research Council Synergy grant ERC-SyG2013-610028 IMBALANCE-P, the Spanish Government grant CGL2016-79835-P, and the Catalan Government grant SGR 2017-1005.

\section{Literature Cited}

Acquisti, C., J. J. Elser, and S. Kumar. 2009. Ecological nitrogen limitation shapes the DNA composition of plant genomes. Molecular Biology and Evolution 26:953-956.

Araujo, M. S., D. I. Bolnick, G. Machado, A. A. Giaretta, and S. F. dos Reis. 2007. Using $\mathrm{d}^{13} \mathrm{C}$ stable isotopes to quantify individual-level diet variation. Oecologia 152:643-654.

Baek, J. H., and S. Lee. 2007. Transcriptome analysis of phosphate starvation response in. Journal of Microbiological Biotechnology 17:244-252.

Baribault, T., R. Kobe, and A. Finley. 2012. Tropical tree growth is correlated with soil phosphorus, potassium, and calcium, though not for legumes. Ecological Monograph 82:189-203.

Bartrons, M., J. Sardans, D. Hoekman, and J. Peñuelas. 2018. Trophic transfer from aquatic to terrestrial ecosystems: a test of the biogeochemical niche hypothesis. Ecosphere 9:e02338.

Baxter, I. R., O. Vitek, B. Lahner, B. Muthukumar, M. Borghi, J. Morrissey, M. L. Guerinot, and D. E. Salt. 2008. The leaf ionome as a multivariable system to detect a plant's physiological status. Proceedings of the National Academy of Sciences USA 105:12081-12086.

Baxter, I., C. Hermans, B. Lahner, E. Yakubova, M. Tikhonova, N. Verbruggen, D. Y. Chao, and D. E. Salt. 2012. 
Biodiversity of mineral nutrient and trace element accumulation in Arabidopsis thaliana. PLoS ONE 7:e35121.

Bearhop, S., C. E. Adams, S. Waldron, R. A. Fuller, and H. MacLeod. 2004. Determining trophic niche width: a novel approach using stable isotope analysis. Journal of Animal Ecology 73:1007-1012.

Begon, M., C. R. Colin, and J. L. Harper. 2006. Ecology: from individuals to ecosystems. Wiley-Blackwell, Oxford, England.

Blonder, B. 2017. Hypervolume concepts in niche- and traitbased ecology. Ecography 41:1441-1445.

Bourgis, F., et al. 1999. S-methylmethionine plays a major role in phloem sulfur transport and is synthesized by a novel type of methyltransferase. Plant Cell 11:1485-1498.

Buescher, E., et al. 2010. Natural genetic variation in selected populations of Arabidopsis thaliana is associated with ionomic differences. PLoS ONE 5:e11081.

Chase, J. M. and M. A. Leibold. 2003. Ecological niches: linking classical and contemporary approaches. University of Chicago, Chicago, Illinois, USA.

Chávez-Vergara, B., et al. 2016. Quercus species control nutrients dynamics by determining the composition and activity of the forest floor fungal community. Soil Biology and Biochemistry 98:186-195.

Chimphango, S. B. M., G. Potgieter, and M. D. Cramer. 2015. Differentiation of the biogeochemical niches of legumes and non-legumes in the Cape Floristic Region of South Africa. Plant Ecology 216:1583-1595.

Chowdhury, P. R., et al. 2015. Differential transcriptomic responses of ancient and modern Daphnia genotypes to phosphorus supply. Molecular Ecology 24:123-135.

Cleveland, C. C., and D. Liptzin. 2007. C:N: P stoichiometry in soil: Is there a 'Redfield ratio' for the microbial biomass? Biogeochemistry 85:235-252.

Colwell, R. K., and T. F. Rangel. 2009. Hutchinson's duality: the once and future niche. Proceedings of the National Academy of Sciences USA 106:19651-19658.

Danger, M., T. Daufresne, F. Lucas, S. Pissard, and G. Lacroix. 2008. Does Liebig's law of the minimum scale up from species to communities? Oikos 117:1741-1751.

Davidson, E. A. W., and R. Howarth. 2007. Nutrients in synergy. Nature 449:1000-1003.

De, C., and S. Bhattacharyya. 2009. First record of the Recent - subRecent diatomaceous earth from the Gangetic alluvial floodplains of. Current Science 96:967-973.

De Bolos, O., and J. Vigo. 2001. Flora dels Països Catalans (I-IV), Editorial Barcino, Barcelona, Spain.

Du, E. 2017. Integrating species composition and leaf nitrogen content to indicate effects of nitrogen deposition. Environmental Pollution 221:392-397.

Durston, D., and R. El-Sabaawi. 2017. Bony traits and genetics drive intraspecific variation in vertebrate elemental composition. Functional Ecology 31:2128-2137.

Elser, J. J., and M. Kyle. 2009. Nutrient availability and phytoplankton nutrient limitation across $\mid$ ra gradient of atmospheric nitrogen deposition. Ecology 90:3062-3073.

Elser, J. J., et al. 2000a. Nutritional constraints in terrestrial and freshwater food webs. Nature 408:578-580.

Elser, J. J., et al. 2000b. Pelagic C:N: P stoichiometry in a eutrophied lake: Responses to a whole-lake food-web manipulation. Ecosystems 3:293-307.

Elser, J. J., K. Hayakawa, and J. Urabe. 2001. Nutrient limitation reduces food quality for zooplankton: Daphnia response to seston Phosphorus enrichment. Ecology 82:898903.

Elser, J. J., et al. 2009. Shifts in Lake N: P stoichiometry and nutrient limitation driven by atmospheric nitrogen deposition. Science 326:835-837.
Elser, J. J., et al. 2010. Atmospheric nitrogen deposition is associated with elevated phosphorus limitation of lake zooplankton. Ecological Letters 13:1256-1261.

Falkowski, P. G., and C. S. Davis. 2004. Natural proportions. Redfield ratios: the uniformity of elemental ratios in the oceans and the life they contain underpins our understanding of marine biogeochemistry. Nature 431:131.

Folch, R., T. Franquesa, and J. M. Camarasa. 1984. Vegetació. Page 404 in Fundació Enciclopèdia Catalana, editor. Història Natural dels PaïsosCatalans (VII). Fundació Enciclopèdia Catalana, Barcelona.

Frenken, T., et al. 2017. Changes in N: P supply ratios affect the ecological stoichiometry of a toxic cyanobacterium and its fungal parasite. Frontieres in Microbiology 8:1-11.

Frisch, D., et al. 2014. A millennial-scale chronicle of evolutionary responses to cultural eutrophication in Daphnia. Ecology Letters 17:360-368.

Ganeshram, R. S., T. F. Pedersen, S. E. Calvert, and R. Francois. 2002. Reduced nitrogen fixation in the glacial ocean inferredlfrom changes in marine nitrogen and phosphorus linventories. Nature 415:156-159.

González, A. L., R. Céréghino, O. Dézerald, V. F. Farjalla, C. Leroy, B. A. Richardson, M. J. Richardson, G. Q. Romero, and D. S. Srivastava. 2018. Ecological mechanisms and phylogeny shape invertebrate stoichiometry: A test using detritus-based communities across Central and South America. Functional Ecology 32:2448-2463.

González, A. L., O. Dézerald, P. A. Marquet, G. Q. Romero, and D. S. Srivastava. 2017. The multidimensional stoichiometric niche. Frontiers in Ecology and Evolution 5:1-17.

Grime, J. P. 1977. Evidence for the existence of three primary strategies in plants and its relevance to ecological and evolutionary theory. American Naturalist 111:1169-1194.

Grossman, A. 2000. Acclimation of Chlamydomonas reinhardtii to its nutrient environment. Protist 151:201-224.

Hartman, W. H., R. Ye, W. R. Horwath, and S. G. A. Tringe. 2017. Genomic perspective on stoichiometric regulation of soil carbon cycling. ISME Journal 11:2652-2665.

Hatton, P. J., C. Castanha, M. S. Torn, and J. A. Bird. 2015. Litter type control on soil $\mathrm{C}$ and $\mathrm{N}$ stabilization dynamics in a temperate forest. Global Change Biology 21:1358-1367.

$\mathrm{He}, \mathrm{M}$., et al. 2016. Influence of life form, taxonomy, climate, and soil properties on shoot and root concentrations of 11 elements in herbaceous plants in a temperate desert. Plant and Soil 398:339-350.

Högberg, M. N., D. D. Myrold, R. Giesler, and P. Högberg. 2006. Contrasting patterns of soil N-cycling in model ecosystems of Fennoscandian boreal forests. Oecologia 147:96-107.

Holt, R. D. 2009. Bringing the Hutchinsonian niche into the 21st century: ecological and evolutionary perspectives. Proceedings of the National Academy of Sciences USA 106:19659-19665.

Huang, X. Y., and D. E. Salt. 2016. Plant Ionomics: From elemental profiling to environmental adaptation. Molecular Plant 9:787-797.

Hutchinson, G. E. 1957. Concluding remarks. Cold Spring Harbor Symposia on Quantitative Biology 22:415-427.

Jeyasingh, P. D., and L. J. Weider. 2007. Fundamental links between genes and elements: Evolutionary implications of ecological stoichiometry. Molecular Ecology 16:4649-4661.

Jeyasingh, P. D., L. J. Weider, and R. W. Sterner. 2009. Genetically-based trade-offs in response to stoichiometric food quality influence competition in a keystone aquatic herbivore. Ecological Letters 12:1229-1237.

Jeyasingh, P. D., et al. 2011. How do consumers deal with stoichiometric constraints? Lessons from functional genomics using Daphnia pulex. Molecular Ecology 20:2341-2352. 
Jeyasingh, P. D., R. D. Cothran, and M. Tobler. 2014. Testing the ecological consequences of evolutionary change using elements. Ecology and Evolution 4:528-538.

Kattge, J., et al. 2011. TRY - a global database of plant traits. Global Change Biology 17:2905-2935.

Kenesi, G., H. M. Shafik, A. W. Kovács, S. Herodek, and M. Présing. 2009. Effect of nitrogen forms on growth, cell composition and $\mathrm{N}_{2}$ fixation of Cylindrospermopsis raciborskii in phosphorus-limited chemostat cultures. Hydrobiologia 623:191-202.

Kerkhoff, A. J., and B. J. Enquist. 2006. Ecosystem allometry: The scaling of nutrient stocks and primary productivity across plant communities. Ecological Letters 9:419-427.

Knight, M. R., A. K. Campbell, S. M. Smith, and A. J. Trewasvas. 1991. Transgenic plant aequorin reports the effects of touch and cold-shock and elicitors on cytoplasmic calcium. Nature 352:524-526.

Lamanna, C. B., et al. 2014. Functional trait species and the latitudinal diversity gradient. Proceedings of the National Academy of Sciences USA 111:13745-13750.

Lapenis, A. G., G. B. Lawrence, A. Heim, C. Zheng, and W. Shortle. 2013. Climate warming shifts carbon allocation from stemwood to roots in calcium-depleted spruce forests. Global Biogeochemical Cycles 27:101-107.

Leal, M. C., O. Seehausen, and B. Matthews. 2017. The ecology and evolution of stoichiometric phenotypes. Trends in Ecology and Evolution 32:108-117.

Lennon, J. T., Z. T. Aanderud, B. K. Lehmkuhl, and D. R Schoolmaster, Jr. 2012. Mapping the niche space of soil microorganisms using taxonomy and traits. Ecology 93:18671879.

Lenton, T. M., and C. Klausmeier. 2007. Biotic stoichiometric controls on the deep ocean N: P ratio. Biogeosciences 4:353367.

Lenton, T. M., and A. J. Watson. 2000. Redfield revisited: 1. Regulation of nitrate, phosphate, and oxygen in the ocean. Global Biogeochemical Cycles 14:225-248.

Lowry, D. B., C. C. Sheng, Z. Zhu, T. E. Juenger, B. Lahner, D. E. Salt, and J. H. Willis. 2012. Mapping of ionomic traits in Mimulus guttatus reveals Mo and Cd QTLs that colocalize with MOT1 homologues. PLoS ONE 7:art e30730.

Mantel, N. 1967. The detection of disease clustering and a generalized regression approach. Cancer Research 27:209-220.

Menge, D. N. L., and L. O. Hedin. 2009. Nitrogen fixation in different biogeochemical niches along a 120 000-year chronosequence in New Zealand. Ecology 90:2190-2201.

Meunier, C. L., M. Boersma, R. El-Sabaawi, H. M. Halvorson, E. M. Herstoff, D. B. Van de Waal, and R. J. Vogt. 2017 From elements to function: toward unifying ecological stoichiometry and trait-based Ecology. Frontiers in Environmental Science 5:Art 18.

Morcuende, R., et al. 2007. Genome-wide reprogramming of metabolism and regulatory networks of Arabidopsis in response to phosphorus. Plant, Cell and Environment 30:85112.

Naples, B. K., and M. C. Fisk. 2010. Belowground insights into nutrient limitation in northern hardwood forests. Biogeochemistry 97:109-121.

Neugebauer, K., M. R. Broadley, H. A. El-Serehy, T. S. George, J. W. McNicol, M. F. Moraew, and P. J. White. 2008. Variation in the Angiosperm Ionome. Physiologia Plantarum 163:1-17.

Novotny, A. M., et al. 2007. Stoichiometric response of nitrogen-fixing and non-fixing dicots to manipulations of $\mathrm{CO}_{2}$, nitrogen, and diversity. Oecologia 151:687-696.

Peñuelas, J., and J. Sardans. 2009. Elementary factors. Nature 460:803-804.
Peñuelas, J., J. Sardans, R. Ogaya, and M. Estiarte. 2008. Nutrient stoichiometric relations and biogeochemical niche in coexisting plant species: Effect of simulated climate change. Polish Journal of Ecology 56:613-622.

Peñuelas, J., et al. 2010. Faster returns on 'leaf economics' and different biogeochemical niche in invasive compared with native plant species. Global Change Biology 16:2171-2185.

Peñuelas, J., et al. 2013. Evidence of current impact of climate change on life: a walk from genes to the biosphere. Global Change Biology 19:2303-2338.

Pereira, F. C., and D. Berry. 2017. Microbial nutrient niches in the gut. Environmental Microbiology 19:1366-1378.

Peterson, A. T. 2011. Ecological niche conservatism: a timestructured review of evidence. Journal of Biogeography 38:817-827.

Pianka, E. R., L. J. Vitt, N. Pelegrin, D. B. Fitzgerald, and K. O. Winemiller. 2017. Toward a periodic table on niches, or exploring the lizard niche hypervolume. American Naturalist 190:601-616

Pierce, S. D., et al. 2016. A global method for calculating plant CSR ecological strategies applied across biomes world-wide. Functional Ecology 31:444-457.

Poxleitner, M., G. Trommer, P. Lorenz, and H. Stibor. 2016. The effect of increased nitrogen load on phytoplankton in a phosphorus-limited lake. Freshwater Biology 61:1966-1980.

Quigg, A., et al. 2003. The evolutionary inheritance of elemental stoichiometry in marine phytoplankton. Nature 425:291-294.

Reinhard, C. T., et al. 2017. Evolution of the global phosphorus cycle. Nature 541:386-389.

Rivas-Martínez, S., F. Fernández-González, J. Loidi, M. Lousa, and A. Penas. 2001. Syntaxonomical Checklist of vascular plant communities of Spain and Portugal to association level. Itinera Geobotany 14:5-341.

Rivas-Ubach, A., J. Sardans, M. Perez-Trujillo, M. Estiarte, and J. Peñuelas. 2012. Strong relationship between elemental stoichiometry and metabolome in plants. Proceedings of the National Academy of Sciences USA 109:4181-4186.

Salt, D. E., I. Baxter, and B. Lahner. 2008. Ionomics and the study of plant ionome. Annual Review of Plant Biology 59:709-733.

Salvagiotti, F., et al. 2017. N:P: S stoichiometry in grains and physiological attributes associated with grain yield in maize as affected by phosphorus and sulfur nutrition. Field Crop Research 203:128-138.

Sardans, J., R. Alonso, J. Carnicer, M. Fernandez-Martinez, M. G. Vivanco, and J. Peñuelas. 2016a. Factors influencing the foliar elemental composition and stoichiometry in forest trees in Spain. Perspectives Plant Ecology, Evolution and Systematics 18:52-69.

Sardans, J., O. Grau, H. Y. H. Chen, I. A. Janssens, P. Ciais, S. Piao, and J. Peñuelas. 2017. Changes in nutrient concentrations of leaves and roots in response to global change factors. Global Change Biology 23:3849-3856.

Sardans, J., I. A. Janssens, R. Alonso, S. D. Veresoglou, M. C. Rillig, T. G. M. Sanders, J. Carnicer, I. Filella, G. FarréArmengol, and J. Peñuelas. 2015. Foliar elemental composition of European forest tree species results from evolutionary traits and the present environmental and competitive conditions. Global Ecology and Biogeography 24:240-255.

Sardans, J., and J. Peñuelas. 2013. Tree growth changes with climate and forest type are associated with relative allocation of nutrients, especially phosphorus, to leaves and wood. Global Ecology and Biogeography 22:494-507.

Sardans, J., and J. Peñuelas. 2014. Climate and taxonomy underlie different elemental concentrations and stoichiometries of forest species: The optimum 'biogeochemical niche'. Plant Ecology 215:441-455. 
Sardans, J., and J. Peñuelas. 2015. Potassium: a neglected nutrient in global change. Global Ecology and Biogeography 24:261-275.

Sardans, J., J. Peñuelas, M. Coll, J. Vayreda, and A. RivasUbach. 2012a. Stoichiometry of potassium is largely determined by water availability and growth in Catalonian forests. Functional Ecology 26:1077-1089.

Sardans, J., J. Peñuelas, and M. Estiarte. 2008a. Changes in soil enzymes related to $\mathrm{C}$ and $\mathrm{N}$ cycle and in soil $\mathrm{C}$ and $\mathrm{N}$ content under prolonged warming and drought in a Mediterranean shrubland. Applied Soil Ecology 39:223-235.

Sardans, J., J. Peñuelas, M. Estiarte, and P. Prieto. $2008 b$. Warming and drought alter $\mathrm{C}$ and $\mathrm{N}$ concentration, allocation and accumulation in a Mediterranean shrubland. Global Change Biology 14:2304-2316.

Sardans, J., J. Peñuelas, and R. Ogaya. 2008c. Drought-induced changes in $\mathrm{C}$ and $\mathrm{N}$ stoichiometry in a Quercus ilex Mediterranean Forest. Forest Science 54:513-522.

Sardans, J., A. Rivas-Ubach, and J. Peñuelas. 2011. Factors affecting nutrient concentration and stoichiometry of forest trees in Catalonia (NE Spain). Forest Ecology and Management 262:2024-2034.

Sardans, J., A. Rivas-Ubach, and J. Penuelas. 2012b. The elemental stoichiometry of aquatic and terrestrial ecosystems and its relationships with organismic lifestyle and ecosystem structure and function: a review and perspectives. Biogeochemistry 111:1-39.

Sardans, J., A. Rivas-Ubach, and J. Peñuelas. 2012c. The C:N: $\mathrm{P}$ stoichiometry of organisms and ecosystems in a changing world: a review and perspectives. Perspectives in Plant Ecology Evolution and Systematics 14:33-47.

Sardans, J., et al. 2016b. Foliar and soil concentrations and stoichiometry of nitrogen and phosphorous across European Pinus sylvestris forests: relationships with climate, $\mathrm{N}$ deposition and tree growth. Functional Ecology 16:676-689.

Schoener, T. W. 1989. The Ecological Niche. Pages 79-114. The Contribution of Ecology to an Understanding of the Natural World. Black-well Scientific, Oxford, England.

Shaul, O. 2002. Magnesium transport and function in plants: the tip of the iceberg. BioMetals 15:309-323.

Sistla, S. A., A. P. Appling, A. M. Lewandowska, B. N. Taylor, and A. A. Wolf. 2015. Stoichiometric flexibility in response to fertilization along gradients of environmental and organismal nutrient richness. Oikos 124:949-959.

Slade, S. 2006. Elements in living organisms. The Rosen Publishing Group, New York, USA.

Sterner, R. W., and J. J. Elser. 2002. Ecological stoichiometry: the biology of elements from molecules to the biosphere. Princenton University Press, New Jersey, USA. pp 464.

Sun, L., et al. 2017. Leaf elemental stoichiometry of Tamarix Lour. species in relation to geographic, climatic, soil, and genetic components in China. Ecological Engineering 106:448-457.

Teurlincx, S., M. Velthuis, D. Seroka, L. Govaert, E. van Donk, D. S. B. Van der Waal, and S. A. Declerk. 2017. Species sorting and stoichiometric plasticity control community C: P ratio of first-order aquatic consumers. Ecology Letters 20(6): 751-760.

Tripler, C. E., S. S. Kaushal, G. E. Likens, and M. Todd Walter. 2006. Patterns in potassium dynamics in forest ecosystems. Ecological Letters 9:451-466.

Turner, C. B., B. D. Wade, J. R. Meyer, B. Sommerfeld, and R. E. Lenski. 2017. Evolution of organismal stoichiometry in a long-term experiment with Escherichia coli. Royal Society Open Science 4:170497.

Tyrrell, T. 1999. The relative in influences of nitrogen and phosphorus on oceanic primary production. Nature 400: $525-530$.

Urbina, I., J. Sardans, C. Beierkuhnlein, A. Jentsch, S. Backhaus, K. Grant, J. Kreyling, and J. Peñuelas. 2015. Shifts in the elemental composition of plants during a very severe drought. Environmental and Experimental Botany 111:6373.

Urbina, I., J. Sardans, O. Grau, C. Beierkuhnlein, A. Jentsch, J. Kreyling, and J. Peñuelas. 2017. Plant community composition affects the species biogeochemical niche. Ecosphere 8: e01801.1.

Violle, C., and L. Jiang. 2009. Towards a trait-based quantification of species niche. Journal of Plant Ecology 2:87-93.

Violle, C., P. B. Reich, S. W. Pacala, B. Enquist, and J. Kattge. 2014. The emergence and promise of functional biogeography. Proceedings of the National Academy of Sciences USA 11:13690-13696.

Wilson, R. P., C. R. McMahon, C. R. Quintana, E. Frere, A. Scolare, G. C. Hays, and C. J. A. Bradshow. 2011. N-dimensional animal energetic niches clarify behavioural options in a variable marine Environmental. Journal of Experimental Biology 214:646-656.

Yamamichi, M., C. L. Meunier, A. Peace, C. Prater, and M. A. Rúa. 2015. Rapid evolution of a consumer stoichiometric trait destabilizes consumer-producer dynamics. Oikos 124:960-969.

Yu, Q., J. J. Elser, N. He, H. Wu, Q. Chen, G. Zhang, and X. Han. 2011. Stoichiometry homeostasis of vascular plants in the inner Mongolia grassland. Oecologia 166:110.

Zamora, P. B., M. B. Cardenas, R. Lloren, and F. P. Siringan. 2017. Seawater-groundwater mixing in and fluxes from coastal sediment overlying discrete fresh seepage zones: a modeling study. Journal of Geophysical Research Oceans 122:6565-6582.

Zederer, D. P., U. Talkner, M. Spohn, and R. G. Joergensen. 2017. Microbial biomass phosphorus and C/N/P stoichiometry in forest floor and A horizons as affected by tree species. Soil Biology and Biochemistry 111:166-175.

Zhang, S. B., J. L. Zhang, J. W. F. Slik, and K. F. Cao. 2012. Leaf element concentrations of terrestrial plants across China are influenced by taxonomy and the environment. Global Ecology and Biogeography 21:809-818.

\section{SUPPORTING INFORMATION}

Additional supporting information may be found in the online version of this article at http://onlinelibrary.wiley.com/doi/ 10.1002/ecy.2652/suppinfo 